\title{
Organic label, bargaining power, and profit sharing in the French fluid milk market
}

\author{
Céline Bonnet* and Zohra Bouamra-Mechemache ${ }^{\dagger}$
}

January $2015^{\ddagger}$

\begin{abstract}
The paper determines how the value added created by the existence of an organic label is shared in a vertical chain among manufacturers and retailers. Using purchase data on the French fluid milk sector, we develop a structural econometric model of demand and supply that takes into account the bargaining power between manufacturers and retailers. Our results suggest that the organic label segment is more profitable as it permits the existence of higher margins. Moreover, an organic label allows manufacturers to achieve more bargaining power relative to retailers and hence to obtain a higher share of total margins. The econometric model is then used to assess the impact of an environmental policy in favor of the organic segment based on a mechanism of price support. Our results suggest that while a subsidy policy towards organic products benefits both manufacturers and retailers, a tax policy toward conventional products benefits manufacturers of national brands at the expense of retailers and manufacturers that provide their private labels. The benefits of such policies on environment is relatively small. They all tend to lower the impact on global warming and land use, but do not reduce eutrophication, acidification and use of energy.
\end{abstract}

\section{Introduction}

Organic food and drink sales have grown from 22.1 billion US dollars in 2002 to almost 63 billion US dollars in 2011, while the global economy has slowed down during the same period (Sahota, 2013). The demand for organics is concentrated in North America (the US mainly) as well as in many European countries (Germany and France, the United-Kingdom and Italy mainly) with 96 percent of organic food sold in those two regions. Organic sales account for

${ }^{*}$ Toulouse School of Economics (INRA, GREMAQ), 21 Allée de Brienne, F-31000 Toulouse France, Tel: +33(0)5 611285 91, cbonnet@toulouse.inra.fr

${ }^{\dagger}$ Toulouse School of Economics (INRA, GREMAQ), 21 Allée de Brienne, F-31000 Toulouse France, Tel: +33 (0)5 61128684 , bouamra@toulouse.inra.fr

¥We thank Elodie Moutengou for her help on database work and estimations. We also thank Stéphane Turolla and Vincent Réquillart for their comments and participants at the 134th EAAE Seminar in Paris, the Third GAEL Conference in Grenoble and the Kick-off meeting of the Project "Competition and Bargaining in Vertical Chains" in Dusseldorf. This paper is part of the "Offrir et Consommer une Alimentation Durable" (OCAD) project funded by the French National Program of Research (Grant Agreement No.ANR - 11 ALID 002 03). Any remaining errors are ours. 
3 percent of total US food sales but the market share of organic products varies depending on the food category and is much larger for categories such as fruit and vegetables and dairy with, respectively, 37 percent and 16 percent of US organic food sales in 2008. ${ }^{1}$ This trend can also be observed in the largest organic markets in Europe. The market share of organic food in Europe represented 1.9 percent of total food expenses in 2007 and reached almost 5 percent in Austria and 3.7 percent in Germany, Denmark, and Luxembourg. As in the US, fruit and vegetables is the most important category, with a share in total organic sales of between 15 percent and 36 percent, and dairy products are the second most important category, with shares between 16 percent and 24 percent (European-Commission, 2010).

The growth in organic markets is driven by a positive willingness to pay for those products (Griffith and Nesheim, 2008). Various consumers' motives explain this premium. Organic food is considered by consumers to be healthier, of higher quality, and less harmful to the environment compared to conventional food as it uses fewer pesticides and artificial fertilizers. Most studies actually find that health and taste are the primary concerns for organic food purchases (Hughner et al., 2007). Griffith and Nesheim (2008) show that product quality is the first concern of English consumers of organic products followed by health and environmental concerns. In addition to health and environmental motives, consumers' sociodemographics as well as social features are also key determinants of organic consumption.

Because consumers are willing to pay a premium for organics, firms may have an interest in developing organic production strategies and enter a profitable market segment. Such a strategy would be profitable only if they can get higher prices in order to compensate for the additional costs for organic products. Processors incur additional costs as they have to pay a higher price for organic milk compared to conventional milk.

Total margins seem to be higher for organic compared to conventional products. For instance, an analysis conducted in a large retail chain in northeastern US (Bezawada and Pauwels, 2013) shows that margins are, on average, 25 percent higher for organic food products. Who benefits from the introduction of these new products and how the margin is split between manufacturers and retailers are issues that are more difficult to assess and remain open questions. On the one hand, retailers play a key role in organic markets. Even if organic products were traditionally sold by specialty shops, conventional retailers have contributed to the expansion of organic markets. First, they list organic products in their stores and account for a large share of the organic food market for many products such as eggs and milk. Second, they are now offering organic products under their own retail brands. They can exert market power from their oligopsonistic position and their buying power relative to manufacturers. This power can rely on alternative market opportunities through the development of their own brands (Bergès-Sennou, 2006, Dobson et al., 2001, Inderst and Mazzarotto, 2008). In this case, manufacturers may not benefit from the value added created in the organic chain. On the other hand, the ability of manufacturers to benefit from organic sales depends on their ability to exercise some market power with respect to retailers. If the supply of organic products is limited and retailers cannot rely on alternative procurement markets for their organic supply, manufacturers may be able to extract a larger share of the margin. For instance, Richards et al. (2011) show that organic growers do earn a larger share of the total margin than non organic growers.

In this paper, we want to analyze whether organic products can confer higher net total

\footnotetext{
${ }^{1}$ Source: USDA website (http://www.ers.usda.gov/topics/natural-resources-environment/organicagriculture/organic-market-overview.aspx\#.Uylt8oWE-8w)
} 
margins compared to conventional ones, how these margins are split between retailers and manufacturers, and how the organic attributes influence the relative bargaining powers of participants in the food chain. We apply our analysis to the French fluid milk market. This food sector is relevant for the analysis of the organic supply chain. First, milk and dairy products comprise one of the main organic food categories. Milk and dairy products represent 15 percent of the total French market for organic products, just behind fruit and vegetables, which represent 17 percent of organic market sales (Agence-Bio, 2011). The organic milk market share has increased steadily over the last ten years. It multiplied by a factor of five between 1998 and 2009. In 2009, it accounted for 8 percent of all fluid milk purchases. Second, organic fluid milk may benefit from a price premium as studies focusing on the fluid milk market show that consumers are willing to pay more for organic characteristics of milk (Dhar and Foltz, 2005, Kiesel and Villas-Boas, 2007). Third, 80 percent of fluid milk sales (in value) occur in conventional stores (Agence-Bio, 2011). Hence, the use of a French representative consumer panel data set collected by KANTAR on household purchases at retailers' stores is appropriate to investigate empirically how organic characteristics influence margin outcomes.

We develop a structural econometric model of the fluid milk vertical chain and estimate retail and wholesale margins for organic and conventional brands as well as the bargaining power of manufacturers and retailers. Contrary to previous structural econometric studies that consider that manufacturers (respectively retailers) have all the bargaining power (Bonnet and Dubois, 2010) and propose take it or leave it contracts to retailers (manufacturers) or act as Stackelberg leaders (Villas-Boas, 2007), we allow for non unilateral bargaining power and model the price negotiation between retailers and manufacturers using a recent methodology developed in Draganska et al. (2010). This methodology enables us to estimate the bargaining power for each pair of manufacturers and retailers and infer the resulting retail and wholesale margin share. Moreover, because organic food is expected to have a positive environmental impact, we assess the environmental impact of organic-friendly policies given the strategic behavior of manufacturers and retailers in the fluid milk sector.

We show that total margins are effectively higher for organic brands compared to conventional ones. The organic products are then more profitable for the milk chain. We also find that organic milk products allow manufacturers to obtain more bargaining power with respect to retailers and hence get a higher share of the total margin on organic products. This result could be explained by the unbalanced procurement market for organic raw milk in favor of manufacturers due to a capacity constrained supply. Finally, results from our simulation show that a price support policy in favor of organic products has a mitigated environmental impact. It slightly reduces the impact on eutrophication, acidification, and energy use but increases CO2 emissions and the use of land.

The paper is organized as follows. We first present the data. We then describe the econometric structural model in the third section. In the fourth section, we discuss the results of the demand and supply models and we use our framework to simulate the impact of an organic-friendly price policy for both firms and retailers. Finally, the last section gives the main conclusions of the paper.

\section{Data on fluid milk purchases}

We use the 2009 data from a French representative consumer panel data of 21,605 households collected by KANTAR. It is a home-scan data set providing detailed information on all the 
purchases of food products. Among other benefits, the data set provides characteristics of the good's purchases (brand, size, organic label product), the store in which it was purchased, the quantity purchased, and its price. The database is composed of 322,755 purchases of fluid milk. We consider all the fluid milk products whatever the origin of the milk (soy, cow, goat) purchased at the French national level. According to our sample, the average annual consumption per person is 72 liters for conventional fluid milk and 6 liters for organic fluid milk.

In France, two major food companies, Lactalis and Sodiaal, face competition from store brands in the fluid milk market. Retailer brands account for 52 percent of the market on average over the 13 periods $^{2}$ considered in 2009 while Lactalis and Sodiaal represent 28 percent of the fluid milk market. ${ }^{3}$ We consider purchases that occur in all retailers' stores. Retailers are grocery store chains that differ by the size of their outlets as well as by the services they provide to consumers. We suppose that all the retailers are national chains and are present in all regions in France. Therefore, consumers based in different regions face the same assortment of products when shopping at a given retailer. We also consider that the main brands are present in most outlets because we consider a market where a few well-known brands are distributed in all outlets. Five main retailers operate in the French retail sector. Among them, three retailer chains are characterized by large outlets while the two other chains have intermediate sized outlets. In addition, we define two aggregates: an aggregate of discounters, that typically have outlets of small to intermediate size, provide only basic services and offer a lowest variety of products, and an aggregate of the remaining retailers.

Retailers offer a set of brands to consumers including national brands (NBs) and private labels (PLs). For each brand, we distinguish between the conventional brand (C) and the organic one $(\mathrm{O})$. Retailers purchase the different brands by negotiating price contracts with each manufacturer. We consider the two main brands produced by Lactalis (Lactel and Bridel) as well as the main brand for Sodiaal (Candia). Those national brands are offered by all retailers except for the aggregate of discounters where the conventional version of only two national brands is available for the consumers. For store brands, retailers are also supposed to negotiate a contract with private firms for their fluid milk brand. Because we do not have any information on the identity of the manufacturer that provides the product sold under the label of the retailer in our dataset, we assume that each retailer deals with a different firm. ${ }^{4}$ In order to assess which assumption on PL production fits the best our data, we implemented statistical tests and used the Rivers and Vuong test as in Bonnet and Dubois (2010) for six different assumptions. ${ }^{5}$ We found that each retailer relies on an independent

\footnotetext{
${ }^{2}$ We divided the 2009 year into thirteen periods of four weeks. We then computed the average price across products and those thirteen periods.

${ }^{3}$ Market shares are defined as follows. We first consider the total market for fluid milk. The market share of a given brand at a given retailer is defined as the ratio of the sum of the quantities of the brand purchased at the selected retailer during a given period and the sum of the quantities of all brands purchased at all of the retailers in the relevant market during the same period.

${ }^{4}$ The two manufacturers, Lactalis and Sodiaal, produce PLs in addition to their NBs. However, other players who only produce PLs are also active on the market (cf. Decision 14-DCC-57, 17/04/2014 of the French Competition authorities relative to the exclusive control by the company ORLAIT (SODIAL) on the liquid milk activity of the cooperative Terra Lacta). Among these players, the main ones are Terra Lacta who sells mostly PLs but also regional brands, and LSDH and Laiterie Saint Pere who produce only PLs. Moreover, the procurement in PL liquid milk by each retailer is organized through an annual call of tender. Thus, the bargaining power of manufacturers depends on whether they negotiate a PL or a NB product.

${ }^{5}$ The six assumptions tested are the following:1) each retailer relies on an independent and single manufac-
} 
Table 1: Descriptive statistics for prices and market hares

\begin{tabular}{|l|c|c|}
\hline \hline & $\begin{array}{c}\text { Prices (in euros per liter) } \\
\text { Mean (standard deviation) }\end{array}$ & $\begin{array}{c}\text { Market shares } \\
\text { (Mean in \%) }\end{array}$ \\
\hline \hline Outside good & & 20.0 \\
\hline Fluid milk & $1.07(0.30)$ & 80.0 \\
\hline Non-organic products & $0.87(0.15)$ & 74.4 \\
Organic products & $1.35(0.24)$ & 5.6 \\
\hline National brands & $1.13(0.32)$ & 27.8 \\
Private labels & $0.92(0.20)$ & 52.2 \\
\hline \hline
\end{tabular}

and single manufacturer for the production of its conventional and organic store brands as this assumption is the one that best fits the data. This assumption allows us to test for the relative bargaining position of retailers with respect to manufacturers when negotiating their own brand. It is often assumed in the literature that retailers vertically integrate with the manufacturing firms for the production of their PLs and have all the bargaining power. We will then be able to test if retailers do have all the bargaining power and if the bargaining power depends on the organic feature of the brands.

Other firms' brands represent only a small market share. Purchases of these other firms' NBs are aggregated in an outside good that represents 20 percent of the market. ${ }^{6}$ Consumers can thus substitute one of the NB or PL fluid milk brands with an alternative product. Taking into account the set of products carried by each retailer, we obtain 46 differentiated products (combination of a brand and a retailer) that compete on the market.

The average price over all products and all periods is 1.07 euros per liter (Table 1). Organic products represent less than 8 percent of the fluid milk purchases. Their market shares have, however, increased over time during the last ten years. The average price of organic products exceeds the average price of conventional brands (NBs and PLs) by 55 percent and this price difference is larger for NBs than for PLs. These numbers are in line with the observed price premium observed in the US with a premium of 60 percent for NBs and 75 percent for PLs in the late 1990s (Glaser and Thompson, 2000). We can also note from our data that PLs are, on average, approximately 20 percent cheaper than NBs.

turer for the production of its conventional and organic store brands (seven manufacturers forthe prduction of PLs); 2) each retailer relies on two independent manufacturers for the production of the conventional and the organic store brands (fourteen manufacturers for the production of PLs); 3) a single manufacturer produces all the stores brands (one manufacturer for the production of PLs); 4) a single manufacturer produces all conventional store brands and another one produces all organic store brands (two manufacturers forthe production of PLs); 5) One of the two considered manfacturer produces all the stores brands (no additional manufacturer for the production of $\mathrm{PL}$ ); 6) The other considered manfacturer produces all the stores brands (no additional manufacturer for the production of PL). The results of the test can be provided upon request.

${ }^{6}$ The outside option is composed of $82 \%$ of non-organic cow milk, $3 \%$ of organic cow milk, $5 \%$ of nonorganic soy milk and $8 \%$ of organic soy milk and the remaining $2 \%$ are goat milks or unknown origin milks. Among the $3 \%$ of organic cow milk, $86 \%$ are purchases from the other seven retailers. The remaining $14 \%$ of organic cow milk concerns very small brands. 


\section{Econometric model of the fluid milk market}

We model the market for fluid milk using a structural model of demand as well as strategic behavior of retailers and manufacturers. The econometric methodology is as follows. We first estimate consumers' preferences in the fluid milk market. Consumers face a choice set composed of the offers of different milk products and each product is defined as the combination of a brand and a retailer. Using demand estimates and modeling retailers' competition, we recover retail margins. We are then able to estimate the relative bargaining power of firms with respect to retailers using exogenous cost variables of fluid milk products. From the estimation of retail margins and bargaining power parameters, we infer the wholesale margins and therefore the total margins for the fluid milk channel.

\subsection{The demand model: a random coefficients logit model}

We use a random coefficients logit model to estimate the demand and the related price elasticities. The indirect utility funtion $V_{i j t}$ for consumer $i$ buying product $j$ in period $t$ is given by:

$$
V_{i j t}=\beta_{b(j)}+\beta_{r(j)}+\alpha_{i} p_{j t}+\rho_{i} l_{j}+\kappa_{t}+\varepsilon_{i j t}
$$

where $\beta_{b(j)}$ and $\beta_{r(j)}$ are, respectively, brand and retailer fixed effects that capture the (time invariant) unobserved brand and retailer characteristics, $p_{j t}$ is the price of product $j$ in period $t, \alpha_{i}$ is the marginal disutility of the price for consumer $i, l_{j}$ is a dummy related to an observed product characteristic (which takes the value of 1 if product $j$ is an organic label product and 0 otherwise), $\rho_{i}$ captures consumer $i$ 's taste for this organic label, $\kappa_{t}$ are time fixed effects, and $\varepsilon_{i j t}$ is an unobserved error term.

We assume that $\alpha_{i}$ and $\rho_{i}$ vary across consumers. Indeed, consumers can have different price disutilities or different tastes for the organic characteristic. We assume that distributions of $\alpha_{i}$ and $\rho_{i}$ are independent and that the parameters have the following specification:

$$
\left(\begin{array}{c}
\alpha_{i} \\
\rho_{i}
\end{array}\right)=\left(\begin{array}{c}
\alpha \\
\rho
\end{array}\right)+\Sigma v_{i}
$$

where $v_{i}=\left(v_{i}^{\alpha}, v_{i}^{\rho}\right)^{\prime}$ is a $2 \mathrm{x} 1$ vector that captures the unobserved consumers' characteristics. $\Sigma$ is a $2 \times 2$ diagonal matrix of parameters $\left(\sigma_{\alpha}, \sigma_{\rho}\right)$ that measures the unobserved heterogeneity of consumers. We assume a parametric distribution for $v_{i}$ denoted by $P_{v}($.$) and$ $P_{\nu}$ is independently and normally distributed with means of $\alpha, \rho$, and standard deviations of $\sigma_{\alpha}, \sigma_{\rho}$.

We can then break down the indirect utility into a mean utility $\delta_{j t}=\beta_{b(j)}+\beta_{r(j)}+\alpha p_{j t}+$ $\rho l_{j}+\kappa_{t}+\xi_{j t}$ where $\xi_{j t}$ captures all unobserved product characteristics and a deviation from this mean utility $\mu_{i j t}=\left[p_{j t}, l_{j}\right]\left(\sigma_{\alpha} v_{i}^{\alpha}, \sigma_{\rho} v_{i}^{\rho}\right)^{\prime}$. The indirect utility is given by $V_{i j t}=\delta_{j t}+\mu_{i j t}+\varepsilon_{i j t}$.

The consumer can decide not to choose one of the considered products. Thus, we introduce an outside option that permits substitution between the considered products and a substitute. The utility of the outside good is normalized to zero. The indirect utility of choosing the outside good is $V_{i 0 t}=\kappa_{t}+\varepsilon_{i 0 t}$.

Assuming that $\varepsilon_{i j t}$ is independently and identically distributed like an extreme value type I distribution, we are able to write the market share of product $j$ at period $t$ in the following way: 


$$
s_{j t}=\int_{A_{j t}}\left(\frac{\exp \left(\delta_{j t}+\mu_{i j t}\right)}{1+\sum_{k=1}^{J_{t}} \exp \left(\delta_{k t}+\mu_{i k t}\right)}\right) d P_{\nu}(\nu)
$$

where $A_{j t}$ is the set of consumers who have the highest utility for product $j$ in period $t$, a consumer being defined by the vector $\left(\nu_{i}, \varepsilon_{i 0 t}, \ldots, \varepsilon_{i J t}\right)$.

The random coefficients logit model generates a flexible pattern of substitutions between products that is driven by the different consumer price disutilities $\alpha_{i}$. Thus, the own- and cross-price elasticities of the market share $s_{j t}$ can be written as:

$$
\frac{\partial s_{j t}}{\partial p_{k t}} \frac{p_{k t}}{s_{j t}}=\left\{\begin{array}{cl}
-\frac{p_{j t}}{s_{j t}} \int \alpha_{i} s_{i j t}\left(1-s_{i j t}\right) \phi\left(v_{i}\right) d v_{i} & \text { if } j=k \\
\frac{p_{k t}}{s_{j t}} \int \alpha_{i} s_{i j t} s_{i k t} \phi\left(v_{i}\right) d v_{i} & \text { otherwise. }
\end{array}\right.
$$

\subsection{Supply models: vertical relationships between processors and retailers}

We consider the fluid milk vertical channel as a two-tier industry consisting of $n_{f}$ upstream firms and $n_{r}$ downstream retailers. Each upstream firm produces a set of goods $G^{f}$ and each downstream firm sells $R^{r}$ products. We consider the market is composed of J differentiated products where a product is a brand sold by a retailer. The marginal cost of producing a product $j$ is denoted by $\mu_{j}$ while the marginal cost at the retail level is denoted $c_{j}$. We denote as $p_{j}$ the retail price of the product $j$ and $w_{j}$ its wholesale price. Retailers' profit functions are given by:

$$
\Pi^{r}(p)=\sum_{j \in R^{r}}\left(p_{j}-w_{j}-c_{j}\right) M s_{j}(p)
$$

where the subscript $t$ is omitted to simplify the notation and $M$ is the total market size. The profit of the firm $f$ from all products sold to retailers is denoted by $\Pi^{f}$ :

$$
\Pi^{f}=\sum_{j \in G^{f}}\left(w_{j}-\mu_{j}\right) M s_{j}(p) .
$$

As in Draganska et al. (2010), we first derive the retail margins. Retail margins result from the retailers' choice of final prices. We assume that retailers compete with each other in Bertrand-Nash fashion in the final fluid milk market and set prices for each product. We then turn to the wholesale price equilibrium, which results from the negotiation between firms and retailers. We assume that the negotiation on wholesale prices is modeled as a Nash bargaining game. We follow Draganska et al. (2010) and consider that each pair of firms and retailers secretly and simultaneously contracts over the wholesale price of the product $j$. Moreover, we assume that firms and retailers have rational expectations, such that the ultimate equilibrium outcome is anticipated by both parties. ${ }^{7}$

\footnotetext{
${ }^{7}$ In in this case, the wholesale prices are determined independently of possible changes to retail prices. For a discussion on the wholesale price negotiation and retailer competition games and the justification of the related assumptions, one might refer to Draganska et al.(2010) and the literature mentioned therein.
} 
Retail Bertrand-Nash equilibrium condition: each retailer $r$ maximizes its profit $\Pi^{r}(p)$. The subgame Nash equilibrium prices of products sold by the retailer $r$ can thus be derived from the first-order conditions of the retailer' s maximization program:

$$
s_{k}(p)+\sum_{j \in R^{r}}\left(p_{j}-w_{j}-c_{j}\right) \frac{\partial s_{j}(p)}{\partial p_{k}}=0, \forall k \in R^{r} .
$$

Using equation (7), the vector of margins $\gamma_{j}=p_{j}-w_{j}-c_{j}$ for retailer $r$ can be written in matrix notation:

$$
\gamma_{r}=\left(I_{r} S_{p} I_{r}\right)^{-1} I_{r} s(p)
$$

where $I_{r}$ is an ownership matrix $(J \times J)$ with element 1 if products $j$ and $k$ are sold by the retailer $r$ and 0 otherwise, $S_{p}$ is the matrix $(J \times J)$ of the market share derivatives with respect to retail prices with general element $\frac{\partial s_{j}(p)}{\partial p_{k}}$, and $s(p)$ is the vector of market shares.

Wholesale price Nash bargaining solution: As emphasized by Shaffer (2001), the main difficulty comes from the linkage across negotiations, which raises arduous questions: a key difficulty is identifying what each manufacturer knows about its rivals' contract terms. Indeed, when negotiating, each manufacturer must conjecture the set of terms its rivals have or have been offered. In equilibrium, this conjecture must be correct but out-of-equilibrium beliefs may be important in determining the bargaining outcome. In the cooperative bargaining approach, this problem is solved by assuming that any bargaining outcome must be bilaterally renegotiation-proof, i.e., no manufacturer-retailer pair can deviate from the bargaining outcome in a way that increases their joint profit, taking as given all other contracts. Following Marx and Shaffer (1999) and Shaffer (2001), we thus assume that bargaining between each retailer-manufacturer pair maximizes the two players' joint profit, taking as given all other negotiated contracts. Moreover, we assume that each player earns its disagreement payoff (i.e., what it would earn from the sales of its other products if no agreement on this product is reached) plus a share $\lambda_{j} \in[0,1]$ (respectively $1-\lambda_{j}$ ) of the incremental gain from trade going to the retailer (respectively to the manufacturer). We follow Draganska et al. (2010) and we assume that a manufacturer negotiates with a given retailer for each of its products, and that each product is negotiated separately with the manufacturer. We also assume that retail prices are not observable when bargaining over the wholesale prices. Then, retail prices are considered as fixed when solving for the bargaining solution (cf. Draganska et al. (2010) for a detailed justification of this assumption).

The equilibrium wholesale price for product $j$ is derived from the bilateral bargaining problem between a firm and a retailer such that each firm and retailer pair maximizes the Nash product: ${ }^{8}$

$$
\left[\pi_{j}^{r}\left(w_{j}\right)-d_{j}^{r}\right]^{\lambda_{j}}\left[\pi_{j}^{f}\left(w_{j}\right)-d_{j}^{f}\right]^{\left(1-\lambda_{j}\right)}
$$

where $\pi_{j}^{f}\left(w_{j}\right)$ and $\pi_{j}^{r}\left(w_{j}\right)$ are, respectively, the profits of the firm and the retailer for product $j$. They are given by:

$$
\begin{aligned}
& \pi_{j}^{f}\left(w_{j}\right)=\left(p_{j}-w_{j}-c_{j}\right) M s_{j}(p)=\gamma_{j} M s_{j}(p) \\
& \pi_{j}^{r}\left(w_{j}\right)=\left(w_{j}-\mu_{j}\right) M s_{j}(p)=\Gamma_{j} M s_{j}(p) .
\end{aligned}
$$

\footnotetext{
${ }^{8}$ Note that conventional and organic milk brands are considered as different products, which implies that conventional and organic products are negotiated independently.
} 
The payoffs the manufacturer and the retailer can realize outside of their negotiations are denoted, respectively, $d_{j}^{f}$ and $d_{j}^{r}$. The retailer could gain $d_{j}^{r}$ if it delists the supplier's product $j$ from its stores but contracts with other suppliers. Similarly, the firm could get profits $d_{j}^{f}$ from the sales of its other products as well as from the sales of products to other retailers if the negotiation fails. If the retail prices are fixed during the negotiation process, the disagreement payoffs $d_{j}^{f}$ and $d_{j}^{r}$ are given by:

$$
\begin{aligned}
d_{j}^{r} & =\sum_{k \in R^{r}-\{j\}} \gamma_{k} M \Delta s_{k}^{-j}(p) \\
d_{j}^{f} & =\sum_{k \in G^{f}-\{j\}} \Gamma_{k} M \Delta s_{k}^{-j}(p)
\end{aligned}
$$

where the term $M \Delta s_{k}^{-j}(p)$ is the change in market shares of product $k$ that occurs when the product $j$ is no longer sold on the market. Those quantities can be derived through the substitution patterns estimated in the demand model as follows:

$$
\Delta s_{k}^{-j}(p)=\int \frac{\exp \left(\delta_{k t}+\mu_{i k t}\right)}{1+\sum_{l=1 \backslash\{j\}}^{J_{t}} \exp \left(\delta_{l t}+\mu_{i l t}\right)}-\frac{\exp \left(\delta_{k t}+\mu_{i k t}\right)}{1+\sum_{l=1}^{J_{t}} \exp \left(\delta_{l t}+\mu_{i l t}\right)} d P_{\nu}(\nu) .
$$

Solving the bargaining problem in equation (9) leads to the following first-order condition:

$$
\lambda_{j}\left(\pi_{j}^{f}-d_{j}^{f}\right) \frac{\partial \pi_{j}^{r}\left(w_{j}\right)}{\partial w_{j}}+\left(1-\lambda_{j}\right)\left(\pi_{j}^{r}-d_{j}^{r}\right) \frac{\partial \pi_{j}^{f}\left(w_{j}\right)}{\partial w_{j}}=0 .
$$

Under the assumption that the matrix of prices for final commodities is treated as fixed when the wholesale prices are decided during the bargaining process, we have $\frac{\partial \pi_{j}^{r}\left(w_{j}\right)}{\partial w_{j}}=$ $-M s_{j}(p)$ and $\frac{\partial \pi_{j}^{f}\left(w_{j}\right)}{\partial w_{j}}=M s_{j}(p)$ from equation (10). Equation (13) can thus be written $\pi_{j}^{f}-d_{j}^{f}=\frac{1-\lambda_{j}}{\lambda_{j}}\left(\pi_{j}^{r}-d_{j}^{r}\right)$. Using equations (10) and (11) the following expression can be derived for the bargaining solution:

$$
\Gamma_{j} M s_{j}(p)-\sum_{k \in R^{r}-\{j\}} \Gamma_{k} M \Delta s_{k}^{-j}(p)=\frac{1-\lambda_{j}}{\lambda_{j}}\left[\gamma_{j} M s_{j}(p)-\sum_{k \in G^{f}-\{j\}} \gamma_{k} M \Delta s_{k}^{-j}(p)\right] .
$$

Using equation (14) for all products $j$, we obtain the matrix of firms' margins:

$$
\Gamma=\sum_{f=1}^{n_{f}} \sum_{r=1}^{n_{r}} \frac{1-\lambda}{\lambda} *\left[\left(I_{f} S I_{f}\right)^{-1}\left(I_{r} S I_{r}\right) \gamma\right] \cdot{ }^{9}
$$

The vector of retail margins $\gamma$ is derived from equation (8), $I_{f}$ is the $(J \times J)$ ownership matrix with element 1 if products $j$ and $k$ are sold by the firm $f$ and 0 otherwise, and $S$ is

\footnotetext{
${ }^{9}$ The $*$ means an element by element multiplication between the vectors $\frac{1-\lambda}{\lambda}$ and $\left[\left(I_{f} S I_{f}\right)^{-1}\left(I_{r} S I_{r}\right) \gamma\right]$.
} 
the $(J \times J)$ matrix with market shares as diagonal elements and changes in market shares otherwise:

$$
S=\left[\begin{array}{cccc}
s_{1} & -\Delta s_{2}^{-1} & \cdots & -\Delta s_{J}^{-1} \\
-\Delta s_{1}^{-2} & s_{2} & \cdots & -\Delta s_{J}^{-2} \\
\vdots & \vdots & \ddots & \vdots \\
-\Delta s_{1}^{-J} & -\Delta s_{2}^{-J} & \cdots & s_{J}
\end{array}\right]
$$

Equation (15) shows the relationship between the wholesale margin on the one hand and the retail margin on the other hand. This relationship first depends on the disagreement payoffs and thus on the market share changes that are determined by the substitution patterns estimated in the demand model. It also depends on the exogenous parameter $\lambda_{j}$, the relative power of the retailer relative to the firm when bargaining over the wholesale price. The higher $\lambda_{j}$, the lower the share of the joint profit the firm will get from the bargaining.

Adding equations (15) and (8) yields the total margin of the firm/retailer pair over product $j:$

$$
p-c-\mu=\left[\sum_{f=1}^{n_{f}} \sum_{r=1}^{n_{r}} \frac{1-\lambda}{\lambda}\left(I_{f} S I_{f}\right)^{-1}\left(I_{r} S I_{r}\right)+I\right]\left(I_{r} S_{p} I_{r}\right)^{-1} I_{r} s(p)
$$

where $I$ is the $(J \times J)$ identity matrix.

Because we do not directly observe firms' marginal production costs as well as retailers' marginal distribution costs, we are not able to determine analytically the bargaining power parameter $\lambda_{j}$. We rather conduct an estimation specifying the overall channel marginal cost $C_{j t}$ for each product $j$. We follow the following specification for the total marginal cost:

$$
C_{j t}=\theta \omega_{j t}+\eta_{j t}
$$

where $\omega_{j t}$ is a vector of cost shifters, $\theta$ is the vector of parameters associated, and $\eta_{j t}$ is the error term that accounts for unobserved shocks to marginal cost. The final equation to be estimated is thus given by:

$$
p=\theta \omega+\left[\frac{1-\lambda}{\lambda} \sum_{f=1}^{n_{f}} \sum_{r=1}^{n_{r}}\left(I_{f} S I_{f}\right)^{-1}\left(I_{r} S I_{r}\right)+I\right]\left(I_{r} S_{p} I_{r}\right)^{-1} I_{r} s(p)+\eta .
$$

We are then able to get an estimate of $\lambda$ for each product. Hence, we can deduce manufacturers' margins from equation (15). Moreover, from the estimates of the cost shifters and the error term of equation (19), we get the estimated total marginal cost, which is the sum of the marginal cost of production and the marginal cost of distribution for each product $j$ at each period $t$.

\section{Results on demand, profit sharing, and environmen- tal policies}

In this section, we first present the results of the random coefficients logit model and thus the consumer substitution patterns in the French fluid milk market. Given the results on price elasticities, we are able to compute retail margins. Using exogenous cost variables, we then estimate the bargaining power of retailers relative to manufacturers that allows us to compute manufacturer margins. Second, we discuss manufacturer, retail, and total margins 
as well as bargaining power estimates. Finally, using the framework developed in relation to consumers, firms, and retailers' behaviors, we implement environmental policies in favor of organic products. We describe the method used and then the results of three scenarios aiming at organic and/or conventional products.

\subsection{Demand results}

We estimated the demand model using individual data and the simulated maximum likelihood method as in Revelt and Train (1997).

This method relies on the assumption that all product characteristics $X_{j t}=\left(p_{j t}, l_{j}\right)$ are independant of the error term $\varepsilon_{i j t}$. However, assuming $\varepsilon_{i j t}=\xi_{j t}+e_{i j t}$ where $\xi_{j t}$ is a productspecific error term varying across periods and $e_{i j t}$ is an individual specific error term, the independence assumption cannot hold if unobserved factors included in $\xi_{j t}$ (and hence in $\varepsilon_{i j t}$ ) such as promotions, displays, and advertising are correlated with observed characteristics $X_{j t}$. For instance, we do not know the amount of advertising that firms expend each month for their brands. This effect is thus included in the error term because advertising might play a role in the choice of fluid milk by households. As advertising is an appreciable share of fluid milk production costs, it is obviously correlated with prices. To solve the problem that omitted product characteristics might be correlated with prices, we use a two-stage residual inclusion approach as in Petrin and Train (2010) and Terza et al. (2008). We then regress prices on instrumental variables, that is input prices, as well as exogenous variables of the demand equation:

$$
p_{j t}=W_{j t} \gamma+\varsigma_{b(j)}+\varsigma_{r(j)}+\tau l_{j}+\eta_{j t}
$$

where $W_{j t}$ is a vector of input price variables, $\gamma$ is the vector of associated parameters, $\eta_{j t}$ is an error term that captures the remaining unobserved variations in prices, and $\varsigma_{b(j)}$, $\varsigma_{r(j)}$ and $l_{j}$ are the exogenous variables from the demand equation. The estimated error term $\widehat{\eta}_{j t}$ of the price equation includes some omitted variables such as advertising variations, promotions, and shelf displays that are not captured by the other exogenous variables of the demand equation and by the cost shifters. Introducing this term in the mean utility of consumers $\delta_{j t}$ allows us to capture unobserved product characteristics varying across time. Prices are now uncorrelated with the new error term $\xi_{j t}+\varepsilon_{j h t}-\pi \widehat{\eta}_{j t}$. We then write:

$$
\delta_{j t}=\beta_{b(j)}+\beta_{r(j)}+\alpha p_{j t}+\rho l_{j}+\kappa_{t}+\xi_{j t}+\pi \widehat{\eta}_{j t}
$$

where $\pi$ is the estimated parameter associated with the estimated error term of the first stage.

In practice, we use the price indexes for the main inputs used in the production of fluid milk, that is, raw milk, energy, and packaging. Cost variables in equation (21) include the price indexes of cardboard, cow milk, and gazole as it is unlikely that input prices are correlated with unobserved determinants of demand for fluid milks. ${ }^{10}$ The fluid milk industry only represents a very small share of the demand for those inputs, which justifies the absence of a correlation between input prices and unobserved determinants of the demand for fluid milks. These variables are interacted with the manufacturer dummies or PL/NB dummies because we expect that manufacturers obtain different prices from suppliers for raw materials and that some characteristics of the inputs (e.g., quality of cardboard) depend on the

\footnotetext{
${ }^{10}$ These indexes are provided by the French National Institute for Statistics and Economic Studies.
} 
manufacturers. Estimation results of the price equation (21) are presented in Table 10 in the Appendix. We can see that the instruments are not weak since almost all of them are significant.

We estimated three models (Table 2). The first model (Model 1) is the demand model without controlling for the endogeneity problem of prices whereas the second model (Model 2) controls for it. The third model (Model 3) controls for both the endogeneity problem of prices and time shocks. ${ }^{11}$ First, the coefficient of the error term is positive and significant. It means that the unobserved part explaining prices is positively correlated with the choice of the alternative and justifies the need to control for the endogeneity problem. Comparison of results from Models 1 and 2 reveals that the price coefficients would be underestimated (in absolute terms) without controlling for the endogeneity problem and that the estimates of the parameters of the model are robust to the two-stage residual inclusion approach. Comparison of results from Models 2 and 3 shows that demand estimates are robust with and without time fixed effects. The estimation results from the demand model 3 are used for the analysis.

On average, the price has a significant and negative impact on utility. Consumers are more sensitive to the price variations of PLs compared to NBs. This is consistent with the idea that consumers might have more loyalty with respect to NBs than to PLs. Results suggest that households prefer organic products to non-organic products, since the mean coefficient is positive. The mean value, however, is very low and the standard deviation is relatively higher, meaning that only half of the households slightly value this characteristic while the others do not. Those results are consistent with previous studies on organic food consumption. For instance, the survey conducted by Hughner et al. (2007) shows that even though consumers have favorable attitudes toward organic food, there is a discrepancy between consumer attitudes and actual consumer purchase behavior and some consumers are not willing to pay as much as the market price premium for organic food (Millock and Hansen, 2002). In an experimental analysis conducted in Germany, van Doorn and Verhoef (2011) show that some consumers are unwilling to pay a price premium for organic products.

The brand fixed effects reveal that the PL products give the highest utility to the households with respect to the other products. This might be explained by the fact that consumers are more sensitive to the level of prices than to the brand they consume when purchasing fluid milk. One reason could be that fluid milk is a quite homogeneous product. The preferences for purchasing in one of the seven major retailers are quite heterogeneous. For the four main retailers, the average consumer values the retailer channel more than the hard discount stores (which is the reference for the retailer fixed effect).

From the demand equation estimation results reported in Table 2, own- and cross-price elasticities of demand among products can be computed. Average own-price elasticities by brands and retailers are given in Table 3. Results show that purchases of fluid milk are more sensitive to changes in own prices for organic milk compared to conventional milk. That result is in line with previous studies on fluid milk consumption in the literature (Glaser and Thompson (2000), Dhar and Foltz (2005), and Alviola and Capps (2010) for the US and

\footnotetext{
${ }^{11}$ Models were estimated using 100 draws for the parametric distribution that represents the unobserved consumer characteristics.
} 
Table 2: Results of the random coefficients logit model

\begin{tabular}{|c|c|c|c|}
\hline Coefficients & Model 1 & Model 2 & Model 3 \\
\hline \multicolumn{4}{|l|}{ Price } \\
\hline Standard deviation & $0.0001(0.0000)$ & $0.0004(0.0000)$ & $0.0022(0.0000)$ \\
\hline Mean $\times$ PL & $-8.7441(0.0001)$ & $-9.1017(0.0002)$ & $-9.1908(0.0003)$ \\
\hline Mean $\times \mathrm{NB}$ & $-3.1223(0.0001)$ & $-3.7164(0.0002)$ & $-3.7362(0.0003)$ \\
\hline \multicolumn{4}{|l|}{ Organic label dummy } \\
\hline Mean & $0.0013(0.0000)$ & $0.0015(0.0000)$ & $0.0113(0.0000)$ \\
\hline Standard deviation & $0.0000(0.0000)$ & $0.2148(0.0001)$ & $0.2280(0.0001)$ \\
\hline \multicolumn{4}{|l|}{ Brand fixed effects } \\
\hline Mean & & & \\
\hline NB1 & $0.1471(0.0000)$ & $0.6835(0.0002)$ & $0.2443(0.0002)$ \\
\hline NB2 & $-1.2851(0.0001)$ & $-0.6184(0.0002)$ & $-1.0564(0.0002)$ \\
\hline NB3 & $0.0358(0.0000)$ & $0.6429(0.0002)$ & $0.2012(0.0002)$ \\
\hline PL & $5.5131(0.0001)$ & $5.7055(0.0002)$ & $5.3245(0.0002)$ \\
\hline \multicolumn{4}{|l|}{ Retailers fixed effects } \\
\hline \multicolumn{4}{|l|}{ Mean } \\
\hline $\mathrm{R} 1$ & $0.3115(0.0000)$ & $0.2897(0.0000)$ & $0.3001(0.0000)$ \\
\hline $\mathrm{R} 2$ & $-0.3318(0.0000)$ & $-0.3473(0.0000)$ & $-0.3353(0.0000)$ \\
\hline $\mathrm{R} 3$ & $0.2765(0.0000)$ & $0.2863(0.0000)$ & $0.2930(0.0000)$ \\
\hline $\mathrm{R} 4$ & $0.1037(0.0000)$ & $0.1217(0.0000)$ & $0.1336(0.0000)$ \\
\hline $\mathrm{R} 5$ & $0.9707(0.0000)$ & $0.9697(0.0000)$ & $0.9840(0.0000)$ \\
\hline $\mathrm{R} 6$ & $-0.1806(0.0000)$ & $-0.1140(0.0000)$ & $-0.1007(0.0000)$ \\
\hline $\mathrm{R} 7$ & - & - & - \\
\hline Time fixed effects & No & No & Yes \\
\hline Error term from the price equation & & $0.8407(0.0003)$ & $0.7751(0.0003)$ \\
\hline Log likelihood & $-920,309$ & $-920,176$ & $-887,401$ \\
\hline Number of observations & 322,755 & 322,755 & 322,755 \\
\hline
\end{tabular}

Standard errors are in parentheses.

Model 1: does not control for the problem of price endogeneity, no time fixed effects.

Model 2: controls for the problem of price endogeneity, no time fixed effects.

Model 3: controls for the problem of price endogeneity, time fixed effects.

NB1, NB2 and NB3 are the dummies for the three national brands; PL is the private label brand. $\mathrm{R} 1, \mathrm{R} 2, \mathrm{R} 3, \mathrm{R} 4, \mathrm{R} 5, \mathrm{R} 6$ and $\mathrm{R} 7$ are the dummies for the seven retailers, $\mathrm{R} 7$ is the reference. 
Table 3: Average own-price elasticities of the brands

\begin{tabular}{|lcc|cc|}
\hline \hline Brands & Characteristic & Own-price elasticity & Retailers & Own-price elasticity \\
\hline \hline NB1 & C & $-3.20(0.47)$ & R1 & $-5.20(2.17)$ \\
NB1 & O & $-5.31(0.28)$ & R2 & $-5.42(2.47)$ \\
NB2 & C & $-3.79(0.60)$ & R3 & $-5.47(2.45)$ \\
NB3 & C & $-3.37(0.42)$ & R4 & $-5.50(2.31)$ \\
NB3 & O & $-5.94(0.87)$ & R5 & $-5.44(2.49)$ \\
PL & C & $-6.17(0.80)$ & R6 & $-5.92(2.24)$ \\
PL & O & $-10.26(0.52)$ & R7 & $-5.13(2.92)$ \\
\hline \hline
\end{tabular}

C: Conventional, O: Organic; the numbers in brackets are standard deviations.

Jonas and Roosen (2008) for Germany). Moreover, average own-price elasticities for NB and PL products suggest that PL purchases are more sensitive to own-price changes compared to NB products: -8.22 and -4.22 respectively. Own-price elasticities are more homogeneous across retailers since they vary on average between -5.13 for the hard discounter aggregate and -5.9 for the aggregate of other retailers.

Cross-price elasticities patterns for conventional versus organic products (cf. Table 11 in the Appendix) show that the price response is asymmetric as in Alviola and Capps (2010). We find that organic milk purchases are less sensitive to a change in the conventional milk price than conventional milk purchases to a change in the price of organic milk. Actually, when the price of a conventional milk product increases by 1 percent, the demand for other conventional milk increases by 0.34 percent while it has only a marginal impact on the demand for organic milk (0.01 percent). On the contrary, an increase in the price of an organic milk product will have a significant impact on the purchases of conventional milk products (0.61 percent) and a limited effect on the demand for other organic milk products.

Table 12 in the Appendix presents price elasticities for national and store brands. We find that the demand for PLs always increases more than the demand for NBs when the price of a national or store brand product increases. Moreover, as for the organic/conventional product substitution patterns, substitution patterns between PL and NB products are asymmetric and PL purchases are more sensitive to changes in the price of NB products than NB purchases to changes in the price of PL products.

\subsection{Bargaining power and price-cost margins}

Using demand estimates, we compute the retail margins using equation (8). We then estimate the parameters of equation (19) using retailers' margins in order to get the estimated bargaining power parameters of the Nash bargaining game and the total margins. Given the bargaining power estimates, we are then able to recover manufacturers' margins thanks to equation (15). The corresponding total marginal cost estimates are consistent with the observed costs. They are equal on average to 0.47 euros per liter for non organic fluid milk and 0.55 euros per liter for organic milk. The difference in the cost is mainly explained by the difference in the price of milk. ${ }^{12}$ Other costs are similar $(0.12 / 0.13$ euros per liter), which

\footnotetext{
${ }^{12}$ The average observed milk production prices over the period 2009-2011 are respectively equal to 0.301 euros/liter for conventional milk (France Agrimer, 2014) and 0.416 euros/liter for organic milk (France Agrimer,
} 
Table 4: Manufacturers and retailers' margins

\begin{tabular}{|lcccc|}
\hline \hline Brands & Characteristic & Manufacturers' margins & Retailers' margins & Total margins \\
\hline \hline NB1 & C & $12.81(10.20)$ & $33.80(5.60)$ & $46.61(7.13)$ \\
NB1 & O & $41.48(2.88)$ & $20.12(1.45)$ & $61.60(3.02)$ \\
NB2 & C & $25.22(11.94)$ & $28.96(5.64)$ & $54.18(6.94)$ \\
NB3 & C & $15.06(8.73)$ & $32.02(4.19)$ & $47.08(7.66)$ \\
NB3 & O & $47.90(8.53)$ & $18.38(2.87)$ & $66.28(9.35)$ \\
PL & C & $17.62(7.55)$ & $17.88(2.67)$ & $35.51(5.39)$ \\
PL & O & $39.57(2.72)$ & $11.54(1.09)$ & $51.11(2.72)$ \\
\hline \hline
\end{tabular}

C: Conventional, O: Organic; the numbers in brackets are standard deviations.

Manufacturers' margins are the average wholesale margins for each brand across retailers and periods.

Retailers' margins are the average retail margins for each brand across retailers and periods.

Total margins are the sum of the average wholesale and retail margins for each brand across retailers and periods.

is consistent as they correspond to processing, packaging, and retailing costs.

As expected, the total margin is higher for NB products compared to PL products. As shown in Table 4, the highest total margin obtained for NB products is 50 percent as high as the total margin for the PLs. The total margin is always lower for the conventional milk brands compared to the organic ones. When splitting these margins between retailers and manufacturers, however, results with respect to the brand and conventional/organic features differ for firms and retailers. Results suggest that retailers' margins are higher for conventional fluid milk than for organic ones: 29 percent and 17 percent respectively on average.

We also find that retailers' margins vary across retailers and range between 11 percent and 34 percent. They are higher for NBs (27 percent) than for PLs (15 percent). ${ }^{13}$ On the contrary, manufacturers' margins are higher for organic brands (42 percent compared to 17 percent for conventional brands), which suggests that manufacturers may benefit more from their organic brand compared to their conventional brands. While the margins at the manufacturing stage are quite low for conventional fluid milk sold under PLs, manufacturers seem to be able, on the contrary, to extract a greater margin from the sales of organic milk.

To get more insight into the impact of conventional/organic attributes of fluid milk on the relative bargaining power of manufacturers, we provide in Table 5 the bargaining power estimates, that is, the shares of the joint profit that are captured by retailers. ${ }^{14}$ The estimated bargaining power of manufacturers is much higher for their organic products than for their conventional ones. Indeed, the bargaining power of retailers for organic products is lower for the NBs (NB1 and NB3) as well as for PL. Retailers thus have less bargaining power than manufacturers for organic brands whatever the retailer/manufacturer pair, in-

2013). The gap between the organic and conventional average milk prices is thus equal to 0.115 euros per liter.

${ }^{13}$ Kusum and Ailawadi (2004) show that the retail margin in per unit value can be smaller for PLs compared to NBs because of their lower retail price.

${ }^{14}$ Cost estimates are given in Table 13 in the Appendix. The cost shifters used to estimate equation (13) are: the plastic price index, the raw milk price index interacted with a dummy for conventional products, a dummy for organic products, and the diesel price index. To be consistent with economic theory, as in Gasmi et al. (1992), we impose the positivity of parameters (except for the additional effect of the organic label). We use, therefore, a non-linear least-squares method to estimate them. All estimated parameters are significant. 
Table 5: Brand-retailer estimates of bargaining power

\begin{tabular}{|l|ccccccc|}
\hline \hline & NB1 C & NB1 O & NB2 C & NB3 C & NB3 O & PL C & PL O \\
\hline \hline R1 & 0.98 & 0.32 & 0.47 & 0.68 & 0.33 & 0.52 & 0.24 \\
R2 & 0.60 & 0.30 & 1.00 & 0.59 & 0.24 & 0.44 & 0.20 \\
R3 & 0.86 & 0.31 & 0.47 & 0.61 & 0.28 & 0.43 & 0.20 \\
R4 & 0.57 & 0.34 & 0.45 & 0.74 & 0.24 & 0.46 & 0.21 \\
R5 & 0.68 & 0.34 & 0.52 & 0.77 & 0.30 & 0.43 & 0.20 \\
R6 & 0.49 & 0.29 & 0.38 & 0.47 & 0.22 & 0.34 & 0.20 \\
R7 & 0.99 & & & 1.00 & & 0.94 & 0.25 \\
\hline \hline
\end{tabular}

cluding for store brands. While the supply of conventional milk is large enough to cover the market ${ }^{15}$ retailers have to secure their procurement of organic milk to satisfy the demand for their organic brand. They have to face an unbalanced procurement market for raw milk in favor of manufacturers due to a capacity constrained supply (the supply was limited while the demand was high at that period). This may allow the upstream sector to exercise more bargaining power in relation to organic brands with respect to retailers. One might ask why retailers should have an incentive to offer organic products on their shelves as they seem to be able to exert less bargaining power for organic milk and their margins are lower for these products. As emphasized by Bezawada and Pauwels (2013) and Aertsens et al. (2009), when offering organic products on their shelves, retailers may not only increase their sales in the fluid milk product category but they can also increase their store profits by enhancing their long-term image through the supply of organic products and differentiate their stores from other retailers' channels. Retailers have an incentive to use organic production as a strategy for product differentiation so as to avoid losing some customers who want to purchase organic products but also to show that they rely on a social responsibility policy.

For conventional brands, results are more contrasted. Retailers do not seem to have a high bargaining power for the PLs (exept for one retailer). Given our framework, this result indicates that the wholesale margins are similar for PLs and NBs but that retailers set lower margins on PLs. They sell their products at a price that is close to the marginal cost as they operate in a more competitive market with more homogeneous products compared to NBs. However, we can observe a large heterogeneity of the bargaining power parameters across brand-retailer pairs. For NB1 and, to a lesser extent, NB3, retailers seem to have more bargaining power.

In order to shed light on the determinants of the bargaining power estimates, we regress the bargaining power parameters on manufacturers and retailers' characteristics. Table 6 presents the results for two models.

The first one (Model A) allows for manufacturer and retailer fixed effects and assesses whether significant differences exist across firms, as well as for the organic label. We find some significant heterogeneity in bargaining power estimates across retailers. As suggested in the bargaining power estimates in Table 5, manufacturers of store brands have a significantly higher bargaining power than manufacturers of NBs. In the second model (Model B), we determine the effect of firms' characteristics rather than fixed effects on the level of bargaining

\footnotetext{
${ }^{15}$ Retailers make use of auctions for their procurement of conventional milk.
} 
Table 6: Regression of the bargaining power on manufacturers and retailers' characteristics

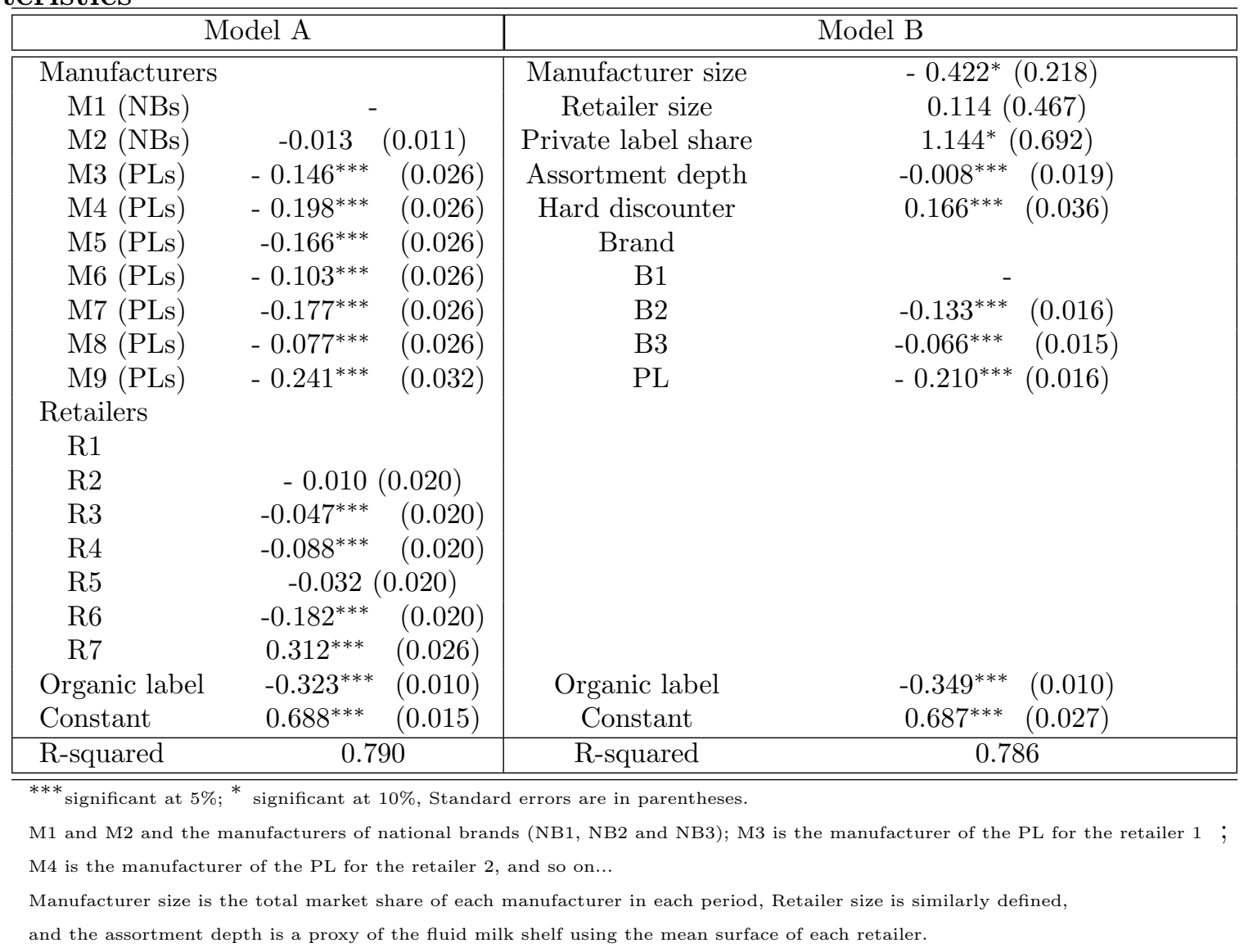

power. The market share of retailers do not have any significant impact on the bargaining power of brand-retailer pairs. On the contrary, the market share of manufacturers seems to influence the bargaining power in favor of manufacturers. Similarly, brand effects are significative. The market share of store brands explains positively the bargaining power estimates, as suggested in the literature (cf. Inderst and Mazzarotto (2008), Kadiyali et al. (2000) and Sudhir (2001)). This is also in line with the empirical results found by Meza and Sudhir (2010). The higher the store brand market share, the higher the bargaining power of the retailer. The proxy of the fluid milk shelf exerts a negative role on the bargaining power estimates. This result can be interpreted as follows. When the fluid milk shelf in a retailer store is limited, the retailer may have more bargaining power as the sale area devoted to NBs is reduced in favor of PLs. On the contrary, when this area is larger, retailers have to display more NBs in order to offer a wider variety to consumers, which increases the bargaining power of manufacturers.

\subsection{Counterfactual experiments}

In this section, we use the framework and the results presented above to analyze what the impact of an environmental tax/subvention would be for manufacturers and retailers. Organic farming systems are supported in many countries for their environmental benefits and the ecosystem services they provide. In particular, organic farming generates fewer residues of 
pesticides than conventional agriculture and contributes to reducing the contamination of water sources and wildlife extinction. Pesticide exposure may also be harmful to farm workers. However, even if the impact of organic farming on environment is generally positive per unit of area, it may not be positive per product unit. In most cases, organic practices reduce environmental impacts per product unit with respect to biodiversity, soil organic matter content (soil quality) and energy requirements but leads to higher land use, eutrophication potential and acidification potential per product unit compared to conventional farming (Tuomisto et al., 2012). In this context, an environmental tax/subvention can be used as a tool to address environmental problems and provide incentives for manufacturers to promote sustainability.

More precisely, we simulate some policy experiments using the estimated marginal costs from the supply contract model and the estimated parameters from the demand model. We consider a possible excise subvention on organic products and/or an excise tax on conventional ones. We denote by $C_{t}=\left(C_{1 t}, . ., C_{j t}, . ., C_{J t}\right)$ the vector of marginal costs for all products in period $t$. To model the impact of a subvention or a tax, we assume that the environmental policy does not affect the bargaining power of retailers on manufacturers and hence we assume that the parameters $\lambda$ have the same values as in Table 5. As wholesale prices depend on retail prices, demand estimates, and the bargaining power between firms and retailers as seen in equation (15), we then only have to determine the vector of equilibrium retail prices consistent with the vector of new marginal costs. We solve the following program:

$$
\min _{\left\{p_{j t}^{*}\right\}_{j=1, . ., J}}\left\|p_{t}^{*}-\Gamma_{t}\left(p_{t}^{*}\right)-\gamma_{t}\left(p_{t}^{*}\right)-\left(C_{t}+\pi\right)\right\|
$$

where $\|$.$\| is the Euclidean norm in R^{J}, \gamma_{t}$ and $\Gamma_{t}$ correspond respectively to the retailer and manufacturer margins for the supply model, and $\pi$ is a fixed positive or negative shock on total marginal cost.

We simulate three scenarios: a subsidy on organic products only that aims to enhance organic production, a tax on conventional products only that discourages conventional production and thus indirectly favors organic production, and a mix of taxes/subsidies. The first scenario consists of decreasing the total marginal cost by 0.04 euros per liter for organic products. The second scenario implements an increase in the total marginal cost of 0.04 euros per liter for conventional products. ${ }^{16}$ The third scenario combines scenarios 1 and $2 .{ }^{17}$

Table 7 presents the impact of the three scenarios on prices and market shares. Given our simulations, it seems that when we implement a subsidy only or a tax only, the subsidy/tax is almost fully transmitted in the final price for consumers. When a subsidy on organic products and a tax on conventional products are implemented simultaneously, the tax is again fully transmitted while the subsidy on organic products is over transmitted for organic PL products, which suggests that firms may strategically make use of the interactions between organic and conventional products. As expected, a subsidy on organic products increases the market share of organic brands and decreases the market shares of conventional ones, but the

\footnotetext{
${ }^{16} \mathrm{~A}$ tax or subsidy of 0.04 euros per liter corresponds to a $10 \%$ tax or subsidy on the marginal cost. We have implemented additional scenarios with a $5 \%$ and $15 \%$ tax or subsidy. We found that environmental impacts (in absolute value) are increasing with the magnitude of the tax.

${ }^{17}$ Given the specification of our demand model, note that the price policy will not change the total milk quantity purchased in our framework but rather reallocate the purchases between the different brands including the outside good. In the case of fluid milk, considering that the total quantity purchased remains unchanged is justified as the fluid milk market is inelastic (the demand price elasticity is equal to -0.15 for fluid milk in France (Bouamra et al., 2008) ).
} 
Table 7: Subvention/taxation effect on price transmission and market shares

\begin{tabular}{|c|c|c|c|c|c|c|c|}
\hline \multirow[b]{2}{*}{ Brands } & \multirow[b]{2}{*}{$\begin{array}{l}\text { Initial MS } \\
\quad \text { in } \%\end{array}$} & \multicolumn{2}{|c|}{$\begin{array}{c}\text { Scenario } 1 \\
\text { Subsidy on organic milk }\end{array}$} & \multicolumn{2}{|c|}{$\begin{array}{c}\text { Scenario } 2 \\
\text { Tax on conventional milk }\end{array}$} & \multicolumn{2}{|c|}{$\begin{array}{c}\text { Scenario } 3 \\
\text { Mix of tax and subsidy }\end{array}$} \\
\hline & & Pass-through & $\begin{array}{l}\text { New MS } \\
\text { in } \%\end{array}$ & Pass-through & $\begin{array}{l}\text { New MS } \\
\text { in } \%\end{array}$ & Pass-through & $\begin{array}{l}\text { New MS } \\
\text { in } \%\end{array}$ \\
\hline NB1 C & & - & 10.0 & $9(0$. & 10.79 & & 10.67 \\
\hline NB1 O & 150 & $0.995(0.003)$ & $1.32(0.16)$ & - & $1.42(0.16)$ & $0.974(0.015)$ & $1.62(0.19)$ \\
\hline NB2 C & 1.39( & - & $1.37(0.12)$ & $1.006(0.009)$ & $1.47(0.12)$ & $1.010(0.011)$ & $1.46(0.12)$ \\
\hline NB3 C & $8.10(\mathrm{C}$ & - & $8.03(0.94)$ & $0.988(0.02)$ & $8.63(0.98)$ & $0.990(0.025)$ & $8.53(0.96)$ \\
\hline NB3 O & 0.70( & $0.995(0.004)$ & 0.81( & - & $0.87(0$ & $0.980(0.017)$ & $1.00(0.30)$ \\
\hline & & & & $0.957(0.019)$ & & & $48.25(2.84)$ \\
\hline PL O & $1.35(0.32)$ & $0.996(0.005)$ & $1.64(0.45)$ & - & $1.76(0.41)$ & $1.124(0.082)$ & $2.51(0.57)$ \\
\hline
\end{tabular}

Standard errors are in parentheses.

impact is quite small and this is true for both NBs and PLs. The tax on conventional milk generates a larger increase in the market share of organic products. This increase, however, does not generate a decrease in the market share of conventional NBs. PLs are the ones that are affected by this policy with a decrease in the market share of their conventional brands of 7 percent. Actually, the tax makes their own conventional label more expensive and because their margin on this product is low, they cannot reduce the price, which makes the NBs more attractive to consumers (the market share of NBs increases slightly). As a result, if we combine a subsidy on organic brands and a tax on conventional ones, we get the highest increase in the market share of organic products and the lowest market share for conventional retailers' brands.

Given these substitution patterns induced by the taxation/subvention policy, we are able to compute the total impact of the policy scenarios on firms and retailers' profits (cf. Table $8)$.

Results are different with the two possible instruments as they lead to non-symmetric impacts on market shares. Both retailers and firms can increase their profits with the subsidy but this is mainly to the benefit of manufacturers. Taxing conventional milk has a huge impact on PLs and as PLs represent the most important market share, the tax leads to a large substitution effect (compared to the subsidy case) in favor of organic products but also in favor of conventional NBs. Manufacturers of NBs are thus able to increase their market share for both their organic and conventional brands to the detriment of PLs. As a result, manufacturers of PLs are the one that are most affected by the tax policy and retailers' profits also decreases as the drop in the market share of PLs is not compensated by retailers' benefit on NBs. ${ }^{18}$ Finally, when we combine a tax and a subsidy policy, the total chain profit is slightly reduced and is in between the profit outcomes of scenarios 1 and 2 . However, it results from a lower profit for manufacturers of PLs and a higher profit for manufacturers of NBs. Manufacturers of NBs benefit from the subsidy on their organic brands. They also benefit from the positive report from PL to NB products generated by the tax policy while manufacturers of PLs are negatively affected.

To evaluate the effective environmental impact of these scenarios, we evaluate the change in some environmental impact indexes. We use the study of van der Werf et al. (2009)

\footnotetext{
${ }^{18}$ The tax impact on profits is consistent with the cross price elasticities presented in Tables 11 and 12 and thus with the results on market shares (cf.Table 7).
} 
Table 8: Subvention/taxation effect on welfare

\begin{tabular}{c|c|c|c}
\hline \hline Variations in millions of euros & $\begin{array}{c}\text { Scenario 1 } \\
\text { Subsidy on organic milk }\end{array}$ & $\begin{array}{c}\text { Scenario 2 } \\
\text { Tax on conventional milk }\end{array}$ & $\begin{array}{c}\text { Scenario 3 } \\
\text { Mix of tax and subsidy }\end{array}$ \\
\hline \hline Total chain profit & 7.55 & -12.97 & -3.39 \\
Total chain profit for NBs & 3.49 & 17.06 & 21.07 \\
Total chain profit for PLs & 4.06 & -30.03 & -24.46 \\
Manufacturer profit & 6.74 & -4.30 & -7.60 \\
Manufacturer profit for NBs & 2.89 & 7.76 & 9.87 \\
Manufacturer profit for PLs & 3.85 & -12.06 & -17.47 \\
Retailer profit & 0.81 & -8.69 & 4.21 \\
Retailer profit for NBs & 0.60 & 9.29 & 11.20 \\
Retailer profit for PLs & 0.21 & -17.98 & -6.99 \\
\hline \hline
\end{tabular}

that provides information on five environmental impact indexes for both conventional and organic milk in France. Except for acidification potential, the indexes are qualitatively similar than the one found in the literature for organic farming. ${ }^{19}$ Organic farming leads to a more important use of land compared to conventional pratices $\left(2.085 \mathrm{~m}^{2} / \mathrm{kg}\right.$ vs $\left.1.374 \mathrm{~m}^{2} / \mathrm{kg}\right)$. Gas emissions negatively influence the quality of air and increase the greenhouse effect, which has a direct impact on the environment (weather changes and loss of ecosystems mainly). Gas emissions are slighly higher for organic than conventional milk (respectively $1082 \mathrm{~kg}$-eq / $1000 \mathrm{~kg}$ of milk for organic and $1037 \mathrm{~kg}$-eq / $1000 \mathrm{~kg}$ for conventional farming systems). ${ }^{20}$ On the contrary, the eutrophication index, which measures the impact on water quality, is lower for organic compared to conventional farms (5.0 versus $7.1 \mathrm{~kg}$ PO4-eq). Similarly, the acidification index, which measures the impact on air pollution, is lower for organic farms (7.6 versus $6.8 \mathrm{~kg}$ SO2-eq). Finally, organic farming requires slightly less energy than conventional farming (2.6 vs $2.8 \mathrm{GJ})$.

Given these values, the simulated environmental impact of implementing a subsidy on organic products is small and mitigated (cf. Table 9). It slightly reduces the impact on eutrophication, acidification, and energy use but slightly increases the CO2 emissions and the use of land. A tax on conventional milk provides slightly larger effects because it affects larger quantities of milk products. Because the main impact of the tax is to reallocate the market shares among products, the global impact of a tax is positive for the climate change and land use indexes but negative for the other forms of environmental damage, including eutrophication. When we combine the two instruments, it increases even more the benefits with respect to climate change and land use but the impacts are worsened for the other environmental indexes.

\footnotetext{
${ }^{19}$ see de Boer (2003), Thomassen et al. (2008a) and, for the French cases, Roger et al. (2007) and Chambaut et al. (2011)). For acidification, contradictory results are found in the literature. For instance, de Boer (2003) and Thomassen et al. (2008b) report opposite results for Sweden. The chosen index values are consistent with other French studies that tend to confirm that organic leads to less acidification than conventional milk. A possible reason for lower acidification potential for organic milk production is that conventional feed contains more protein and leads thus to higher ammonia emissions (Tuomisto et al., 2012). The climate change index measures the impact on carbon emissions (CO2).

${ }^{20}$ Emissions are lower for organic production than for conventional farming systems when they are measured per unit of land. They are, however, higher when emissions are given per milk production unit. This is explained by the lower productivity of organic systems compared to organic ones. CO2 emissions are higher because organic farming requires a larger share of long-term grasslands.
} 
Table 9: Environmental impact of subvention/taxation scenarios

\begin{tabular}{l|l|c|c|c}
\hline \hline & Unit & $\begin{array}{c}\text { Scenario 1 } \\
\text { Subsidy on organic milk }\end{array}$ & $\begin{array}{c}\text { Scenario 2 } \\
\text { Tax on conventional milk }\end{array}$ & $\begin{array}{c}\text { Scenario 3 } \\
\text { Mix of tax and subsidy }\end{array}$ \\
\hline \hline Climate change & $10^{6} \mathrm{~kg} \mathrm{CO}$ equivalents & $+0.93(+0.05 \%)$ & $+1.21(0.06 \%)$ & $+2.46(+0.12 \%)$ \\
Eutrophication & $10^{3} \mathrm{~kg} \mathrm{NO} \mathrm{NO}_{3}^{-}$equivalents & $-43.49(-0.32 \%)$ & $-56.72(-0.42 \%)$ & $-114.90(-0.86 \%)$ \\
Acidification & $10^{3} \mathrm{~kg} \mathrm{SO} 2$ equivalents & $-16.56(-0.11 \%)$ & $-21.61(-0.14 \%)$ & $-43.77(-0.30 \%)$ \\
Energy use & $10^{3} \mathrm{Gj}$ & $-4.10(-0.07 \%)$ & $-5.40(-0.10 \%)$ & $-10.94(-0.20 \%)$ \\
Land use & $10^{3} \mathrm{~m}^{3}$ & $+14.72(+0.55 \%)$ & $+19.20(+0.72 \%)$ & $+38.90(+1.45 \%)$ \\
\hline \hline
\end{tabular}

\section{Conclusion}

In this paper, we assess how the value added created by the existence of an organic label in a vertical chain is shared among manufacturers and retailers in the French fluid milk market. First of all, our study contributes to the literature on the consumption of organic products. We show that French consumers slightly value the organic attribute of fluid milk products on average but only half of households value this characteristic positively while the others do not. Moreover, cross-price elasticity estimates suggest an asymmetric pattern for organic and conventional fluid milk purchasing such that organic milk purchases are less sensitive to a change in the conventional milk price than conventional milk to a change in the price of organic milk.

Second, we estimate the relative bargaining power of upstream firms with respect to retailers using exogenous cost variables of fluid milk products and next infer the total margins and how these margins are split into a wholesale margin and a retail margin. Given the substitutability patterns between the different brands that have different characteristics (NB, PL, conventional milk, organic milk), we show that an organic label leads to higher total margins and provides a higher level of bargaining power to manufacturers. It transpires that firms' margins (respectively retailers' margins) are higher (lower) for organic products compared to conventional milk. Moreover, we show that retailers' margins on PLs are lower for organic milk and that their relative bargaining power is low even if they sell the products using their own label. Furthermore, the bargaining power is more in favor of retailers for conventional products but there exists a large heterogeneity depending on the retailer and the brand pair.

Based on the estimated margins for retailers and manufacturers, we infer the impact of an environmental policy on this market. Interestingly, we show that a subsidy policy benefits both manufacturers and retailers while a tax policy benefits manufacturers of national brands at the expense of manufacturers of private labels and retailers. However, the benefits of such policies on environment is relatively small. While a subsidy tends to be more efficient to decrease the impact on global warming and land use, it would not be efficient to reduce eutrophication, acidification and use of energy. The use of a tax on conventional products would amplify these findings.

This study thus yields insights into the ability of firms to countervail the buying power of retailers through the use of organic labeling. It is based on a structural econometric model. This model assumes a Nash bargaining between retailers and manufacturers to take explicitly into account the relative bargaining power of each actor. It also assumes a linear contract between each of the retailer and manufacturer pairs with unobservability of retail prices at the time of the negotiation. These assumptions, even if they may appear restrictive, allow for the estimation of bargaining power. In future works, we first want to specify an econometric model that relaxes some of these asumptions. More particularly, we want to determine how results are changed when retail prices can be observed by firms. Second, we 
also want to consider how results are affected when the manufacturer/retailer pair has the possibility of negotiation on the bundle of brands produced by the retailer compared to a separate negotiation product by product. When negotiating on a bundle, the manufacturer may increase its bargaining power not only in relation to the organic brand but also in relation to its non organic brands.

\section{Appendix}

\subsection{Results on price equation}

Table 10: Results on price equation

\begin{tabular}{|c|c|}
\hline & Coefficient (standard error) \\
\hline Cow milk $\times$ OL & $0.002(0.001)$ \\
\hline 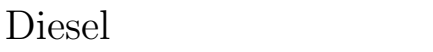 & $-0.007^{* * *}(0.003)$ \\
\hline Cardboard × Manuf2 & $-0.022^{*}(0.013)$ \\
\hline Retailer fixed Effects & \\
\hline $\mathrm{R} 1$ & $0.060^{* * *}(0.007)$ \\
\hline $\mathrm{R} 2$ & $0.091^{* * *}(0.000)$ \\
\hline $\mathrm{R} 3$ & $0.106^{* * *}(0.000)$ \\
\hline $\mathrm{R} 4$ & $0.123^{* * *}(0.000)$ \\
\hline $\mathrm{R} 5$ & $0.102^{* * *}(0.000)$ \\
\hline $\mathrm{R} 6$ & $0.207^{* * *}(0.000)$ \\
\hline Organic label & $0.305^{* * *}(0.106)$ \\
\hline F-test of IVs & $2.35^{* * *}(0.017)$ \\
\hline R-squared & 0.988 \\
\hline Number of observations & 590 \\
\hline
\end{tabular}

*** significant at $5 \% ;{ }^{*}$ significant at $10 \%$ 


\subsection{Results on price elasticities}

Table 11: Own and cross-price elasticities for conventional and organic products

\begin{tabular}{|l|c|cc|}
\hline \hline & Own-price elasticities & \multicolumn{2}{|c|}{ Aggregated cross-price elasticities } \\
\hline & & Conventional & Organic \\
Conventional & -4.15 & 0.34 & 0.01 \\
Organic & -7.38 & 0.61 & 0.02 \\
\hline \hline
\end{tabular}

Own-price elasticities for conventional and organic milk are computed as the average over products and time periods of own-price elasticities of conventional or organic products respectively.

Aggregated cross-price elasticities are computed as the global change

either for other conventional milks (the third column) or other organic milk (the fourth column)

when the price of a conventional product (the third row) or the price of an organic product (the fourth row) varies.

Table 12: Own and cross-price elasticities for national brand and store brand products

\begin{tabular}{|l|c|cc|}
\hline \hline & Own-price elasticities & \multicolumn{2}{|c|}{ Aggregated cross-price elasticities } \\
\hline & & National brands & Private labels \\
National brands & -4.23 & 0.06 & 0.44 \\
Private labels & -8.21 & 0.13 & 0.83 \\
\hline \hline
\end{tabular}

Own-price elasticities for conventional and organic milk are computed as the average over products and time periods of own-price elasticities of conventional or organic products respectively.

Aggregated cross-price elasticities are computed as the global change

either for other conventional milks (the third column) or other organic milk (the fourth column)

when the price of a conventional product (the third row) or the price of an organic product (the fourth row) varies.

\subsection{Results on equation (19)}

Note that the results for $\lambda$ are presented in Table 5 and are all significant. 
Table 13: Results on the final equation (13)

\begin{tabular}{|l|c|}
\hline \hline & Coefficient (standard error) \\
\hline \hline Plastic price & $0.0002^{* * *}(0.00003)$ \\
Cow milk & $0.0007^{* * *}(0.00006)$ \\
Cow milk $\times$ OL & $0.0009^{* * *}(0.00001)$ \\
Diesel & $0.0019^{* * *}(0.00010)$ \\
Energy & $0.0007^{* * *}(0.00008)$ \\
Parameters $\frac{1-\lambda}{\lambda}$ not shown & \\
R-squared & 0.8943 \\
Number of observations & 590 \\
\hline \hline
\end{tabular}

*** significant at $5 \%$; 


\section{References}

Aertsens, J., Mondelaers, K., and Van Huylenbroeck, G. (2009). Differences in retail strategies on the emerging organic market. British Food Journal, 111 (2):138-154.

Agence-Bio (2011). Les filières laitières biologiques. Technical report.

Alviola, P. A. and Capps, O. (2010). Household demand analysis of organic and conventional fluid milk in the united states based on the 2004 nielsen homescan panel. Agribusiness, 26(3):369 - 388.

Bergès-Sennou, F. (2006). Store loyalty, bargaining power and the private label production issue. European Review of Agricultural Economics, 33(3):315 - 335.

Bezawada, R. and Pauwels, K. (2013). What is special about marketing organic products? how organic assortment, price, and promotions drive retailer performance. Journal of Marketing, 77(1):31 - 51.

Bonnet, C. and Dubois, P. (2010). Inference on vertical contracts between manufacturers and retailers allowing for nonlinear pricing and resale price maintenance. RAND Journal of Economics (Blackwell Publishing Limited), 41(1):139 - 164.

Bouamra, Z., Réquillart, V., and Soregaroli, C. (2008). Demand for dairy products in the eu. Food Policy, 33:644-656.

Chambaut, H., Moussel, E., Pavie, J., Coutard, J. P., Galisson, B., Fiorelli, J.-L., and Leroyer, J. (2011). Profils environnementaux des exploitations d'élevage bovins lait et viande en agriculture biologique et conventionnelle: enseignements du projet cedabio. Rencontres autour des recherches sur les ruminants, pages 53-56.

de Boer, I. J. (2003). Environmental impact assessment of conventional and organic milk production. Livestock Production Science, 80(1):69-77.

Dhar, T. and Foltz, J. D. (2005). Milk by any other name . . consumer benefits from labeled milk. American Journal of Agricultural Economics, 87:214 - 228.

Dobson, P. W., Clarke, R., Davies, S., and Waterson, M. (2001). Buyer power and its impact on competition in the food retail distribution sector of the european union. Journal of Industry, Competition and Trade, 1(3):247-281.

Draganska, M., Klapper, D., and Villas-Boas, S. B. (2010). A larger slice or a larger pie? an empirical investigation of bargaining power in the distribution channel. Marketing Science, 29(1):57 - 74 .

European-Commission (2010). An analysis of the eu organic sector. Technical report, Directorate General for Agriculture and Rural Development, France.

France Agrimer, F. (2013). Sondage mensuel - lait de vache biologique. Technical report, Marchés, études et prospective - Service Bases d'information économique - unité Enquêtes et données filières. 
France Agrimer, F. (2014). Les filières animales terrestres et aquatiques. bilan 2013 and perspectives 2014. Technical report.

Gasmi, F., Laffont, J. J., and Vuong, Q. (1992). Econometric analysisof collusive behaviorin a soft-drink market. Journal of Economics $\&$ Management Strategy, 1(2):277-311.

Glaser, L. K. and Thompson, G. D. (2000). Demand for organic and conventional beverage milk. Paper presented at the Western Agricultural Economics Asociation Annual Meetings, Vancouver, British Columbia, June 29-July 1, 2000.

Griffith, R. and Nesheim, L. (2008). Household willingness to pay for organic products. CEPR Discussion Papers 6905, C.E.P.R. Discussion Papers.

Hughner, R. S., McDonagh, P., Prothero, A., Shultz II, C. J., and Stanton, J. (2007). Who are organic food consumers? a compilation and review of why people purchase organic food. Journal of Consumer Behaviour, 6:1-17.

Inderst, R. and Mazzarotto, N. (2008). Buyer power in distribution. ABA Antitrust Section Handbook, Issues in Competition Law and Policy (W. D. Collins, ed.).

Jonas, A. and Roosen, J. (2008). Demand for milk labels in germany: organic milk, conventional brands, and retail labels. Agribusiness, 24(2):192 - 206.

Kadiyali, V., Chintagunta, P., and Vilcassim, N. (2000). Manufacturer-retailer channel interactions and implications for channel power: An empirical investigation of pricing in a local market. Marketing Science, 19(2):127 - 148.

Kiesel, K. and Villas-Boas, S. B. (2007). Got organic milk? consumer valuations of milk labels after the implementation of the usda organic seal. Journal of Agricultural ES Food Industrial Organization, 5(1):art 4.

Kusum, L. and Ailawadi, B. H. (2004). An empirical analysis of the determinants of retail margins: The role of store-brand share. Journal of Marketing, 68 (1):147-165.

Marx, L. M. and Shaffer, G. (1999). Predatory accommodation: Below-cost pricing without exclusion in intermediate goods market. RAND Journal of Economics (RAND Journal of Economics), 30(1):22 - 43 .

Meza, S. and Sudhir, K. (2010). Do private labels increase retailer bargaining power? Quantitative Marketing and Economics, 8 (3):333-363.

Millock, K. and Hansen, L. (2002). Willingness to pay for organic foods: A comparison between survey data and panel data from denmark. Paper presented at Paper presented at the 12th annual EAERE (European Association of Environmental and Resource Economists) Conference, June 2002, Monterey, USA.

Petrin, A. and Train, K. (2010). A control function approach to endogeneity in consumer choice models. Journal of Marketing Research (JMR), 47(1):3 - 13.

Revelt, D. and Train, K. (1997). Mixed logit with repeated choices: Households' choices of appliance efficiency level. The Review of Economics and Statistics, pages 647-657. 
Richards, T. J., Acharya, R. N., and Molina, I. (2011). Retail and wholesale market power in organic apples. Agribusiness, 27(1):62-81.

Roger, F., Van der Werf, H., Kanyarushoki, C., and EQUIPE, S. R. D. B. (2007). Systèmes bovins lait bretons: Consommation d'énergie et impacts environnementaux sur l'air, l'eau et le sol. Rencontres autour des recherches sur les ruminants, pages 33-36.

Sahota, A. (2013). The global market for organic food \& drink. The World of Organic Agriculture, Statistics and Emerging Trends 2013.

Shaffer, G. (2001). Bargaining in distribution channels with multiproduct retailers.

Sudhir, K. (2001). Structural analysis of manufacturer pricing in the presence of a strategic retailer. Marketing Science, 20(3):244.

Terza, J., Basu, A., and Rathouz, P. (2008). Two-stage residual inclusion estimation addressing endogeneity in health econometric modeling. Journal of Health Economics, 27 (3):531-543.

Thomassen, M., Van Calker, K., Smits, M., Iepema, G., and De Boer, I. (2008a). Life cycle assessment of conventional and organic milk production in the netherlands. Agricultural systems, 96(1):95-107.

Thomassen, M. A., Dalgaard, R., Heijungs, R., and de Boer, I. (2008b). Attributional and consequential lca of milk production. The International Journal of Life Cycle Assessment, 13(4):339-349.

Tuomisto, H., Hodge, I., Riordan, P., and Macdonald, D. (2012). Does organic farming reduce environmental impacts?-a meta-analysis of european research. Journal of environmental management, 112:309-320.

van der Werf, H. M., Kanyarushoki, C., and Corson, M. S. (2009). An operational method for the evaluation of resource use and environmental impacts of dairy farms by life cycle assessment. Journal of Environmental Management, 90:3643-3652.

van Doorn, J. and Verhoef, P. C. (2011). Willingness to pay for organic products: Differences between virtue and vice foods. International Journal of Research in Marketing, 28(3):167 $-180$.

Villas-Boas, S. B. (2007). Vertical relationships between manufacturers and retailers: Inference with limited data. Review of Economic Studies, 74(2):625 - 652 . 